\title{
Society news
}

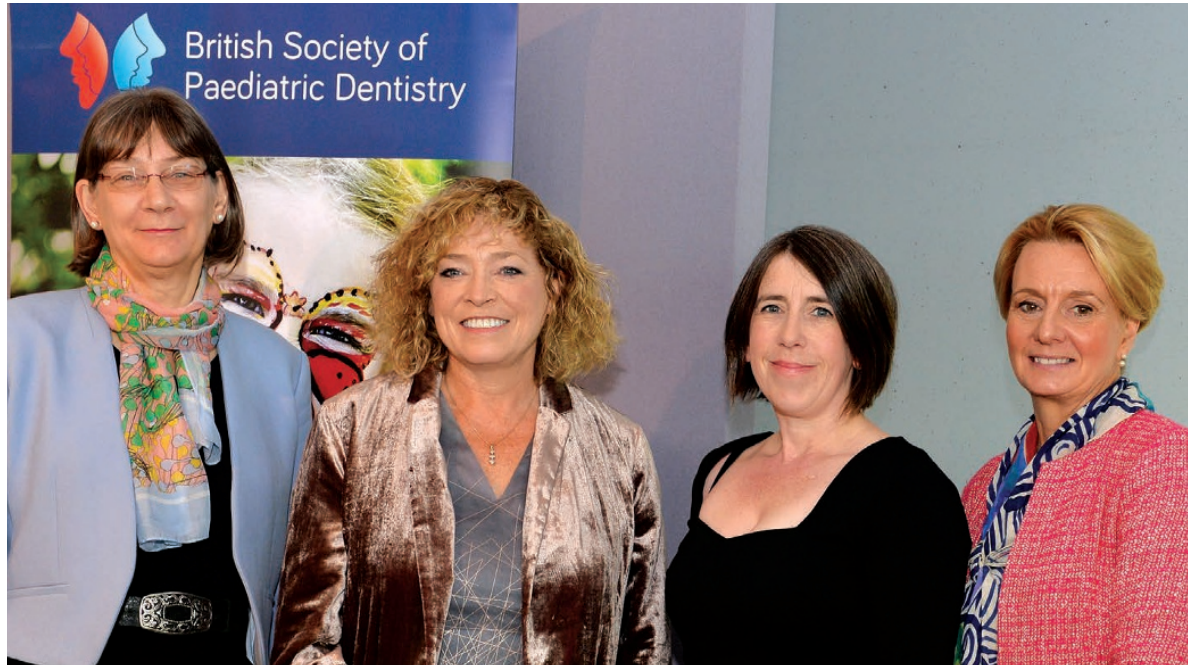

(L-r) Margie Taylor (CDO for Scotland), Colette Bridgman (CDO for Wales), Claire Stevens (BSPD President), Sara Hurley (CDO for England)

\section{British Society of Paediatric Dentistry} Starting Well launch

The launch of the new Starting Well scheme has been welcomed by BSPD as an important step in trying to reduce oral health inequalities in children. Starting Well is to operate in 13 areas of England where children's oral health is worst: Salford, Rochdale, Oldham, Bolton, Middlesborough, Blackburn, Kingston-upon-Hull, Wakefield, Blackpool, Leicester, Luton, Ealing and Slough. Dental practices will, among other initiatives, hold open days and family events to improve access for young children.

\section{Conference showcases collaboration}

The BSPD 2017 conference in Manchester in September, with a theme of Creative Collaboration, proved to be an exemplary showcase of multi-disciplinary working, featuring examples of professionals thinking beyond their specialty and department in the interests of children.

Delegates at Salford Quays' Lowry Arts Centre heard professionals from a variety of health-related backgrounds in Manchester discuss their innovative ways of working, as well as the impact they have, whether stepchanges in improving children's oral health to progressive alliances and breakthroughs in diagnosis and care.

A high point of the conference was the session in which three of the UK's four Chief Dental Officers spoke (pictured). While they were not directly collaborating, all three identified similar aims and issues. Scotland's
Childsmile is an acknowledged role model and all three CDOs praised the Dental Check by One campaign just launched by the BSPD.

\section{Outstanding Innovation Award}

The BSPD's Outstanding Innovation Award in 2018 is open for entries. The award, now in its second year, was established to give recognition to projects judged by the Society to be most effective at improving children's oral health. The winner of the award is given the opportunity to speak at BSPD's conference.

Entries should be a maximum of 400 words; you must be a BSPD member; and the closing date is 31 January 2018. Email administrator@bspd.co.uk.

\section{British Association of Oral \& Maxillofacial} Surgeons

BAOMS member Jerry Ryan, consultant oral and maxillofacial surgeon based at City Hospitals Sunderland, is one of the very first cosmetic surgeons in the country to be certified by the Royal College of Surgeons of England (RCSEng) to practise cosmetic surgery.

The move towards robust regulation in cosmetic surgery was led by RCSEng and developed in consultation with BAOMS and other specialities in the field. It followed the publication in 2013 of NHS Medical Director Professor Sir Bruce Keogh's independent review that recommended better regulation, training and proper redress if things go wrong.

Other applications are in the pipeline and more surgeons will be on the register later this year.

\section{British Orthodontic Society}

BOC

More than 1,100 delegates attended the British Orthodontic Conference in Manchester in September where 64 presentations were held across three parallel sessions on each of three days. With a theme of 'Back to the Future', many of the speakers were inspired to reflect on the past but also predict what might be on the horizon, whether discussing supplies, techniques, equipment or materials.

An eagerly awaited highlight of the conference was Nigel Harradine's talk 'Forty years in orthodontics, what has changed?' He identified some landmark innovations which had moved the science and practice of orthodontics forward but which had frequently been scorned when first advocated. Sometimes early versions of a new product or concept were not fully convincing; at other times, orthodontists didn't want to leave their comfort zone and current skill set.

\section{Retention campaign launched}

At its conference, BOS launched a viral \#HoldthatSmile campaign to build awareness of the fact that retainers are for life. BOS is encouraging the whole dental team to play a role in stressing the importance of retention to orthodontic patients, to make sure patients are motivated to commit to wearing retainers for life.

A Hold that Smile animation and a captioned short film which communicates the benefits of retainers are now available for orthodontic and dental clinics to share with their patients:

https://www.youtube.com/

watch? $\mathrm{v}=5 \mathrm{wCIFj} 1 \mathrm{Stzc}$

https://www.bos.org.uk/Public-Patients/ Orthodontic-Retention-for-Patients

\section{British Society for Oral and Dental \\ Research}

The BSODR conference was hosted by the University of Plymouth in early September, showcasing the latest in dental research.

Presented research ranged from dentistry in the community to 'smart fillings', new and potential lab-based therapies, nanotechnology, diet and behaviour and dental professionalism.

Delegates also enjoyed a welcome reception at the National Marine Aquarium and a gala dinner in the Officers' Mess at Royal Marine Stonehouse Barracks. 